\title{
Trans-radial percutaneous coronary intervention in dextrocardia: case report and review of literature
}

\begin{abstract}
Dextrocardia (DC) is a rare congenital anomaly with a prevalence of 1 in 10,000 births. The incidence of coronary artery disease in such patients is thought to be similar to that of the general population. Percutaneous coronary intervention (PCI) in dextrocardia presents several challenges due to abnormal location of the heart, mirror image pattern of aortic arch and its branches, and abnormal coronary origin and orientation. There have been few case reports of PCI in patients with dextrocardia and they mostly have been done via transfemoral access. We present first case of successful transradial PCI using a 5Fr system in a patient with DC. Literature review of technical considerations, including our own recommendations for guide catheter selection is discussed. We also review the anatomic variations and epidemiology of DC. Although access-complications for transradial PCI is known to be lower than that of the transfemoral approach but challenges in technique have limited the popularity of the former. Our report demonstrates the safety and feasibility of transradial angiography and PCI in the rare patient with DC
\end{abstract}

Keywords: acute coronary syndrome, dextrocardia, transradial intervention, percutaneous coronary intervention
Volume I Issue 2 - 2014

\author{
Adel El-Hosieny \\ Department of Cardiology, University Medical Center Utrecht, \\ Netherlands
}

Correspondence: Adel El Hosieny, Department of Cardiology, University Medical Center Utrecht, Heidelberglaan 100, 3584 CX Utrecht, Netherlands, Tel 3I-88-755-5555, Email adelhosieny@hotmail.com

Received: May 12, 2014 | Published: May 28, 2014
Abbreviations: DC, dextrocardia; PCI, percutaneous coronary intervention; $\mathrm{CAD}$, coronary artery disease; ECG, electrocardiogram; LAD, left anterior descending artery; Fr, french; LAO, left anterior oblique; RAO, right-anterior-oblique; RCA, right coronary artery; JR4, judkins right $4 \mathrm{~cm}$; JL4, judkins left 4-cm; LCX, left circumflex; BMW, balanced middle weight

\section{Introduction}

Situs inversus with dextrocardia is a rare congenital anomaly of development characterized by a mirror image position of the heart and abdominal viscera. ${ }^{1,2}$ Although it is rare clinical phenomenon, the association with coronary artery disease (CAD) is the same frequency as in the general population. ${ }^{3}$ Few cases of situs inversus and dextrocardia complicated with $\mathrm{CAD}$ were reported before. The coronary angiography and percutaneous coronary intervention (PCI) in these patients is technically difficult and requires some modifications, such as mirror-image angiographic views, proper catheter selection and catheter manipulation for selective cannulation of the coronaries. Here we report a case of a male patient with dextrocardia and CAD was successfully treated with transradial PCI.

\section{Case report}

A 55-year old man was transferred from one of our referring hospitals with early post infarct unstable angina, having chest pain in the right side of the chest radiating to the right shoulder and the back, following an anterior ST-elevation myocardial infarction for which he had received thrombolytic therapy. He was a known case of dextrocardia with Kartagener syndrome, diabetic and smoker. Physical examination was unremarkable except for findings consistent with dextrocardia. Apart from raised troponine-I and blood sugar, his routine laboratory tests were within normal values. 12-lead
Electrocardiogram (ECG) showed a negative P wave lead-I and aVL and positive $\mathrm{P}$ and $\mathrm{R}$ waves in aVR together with $\mathrm{Q}$ waves in inferior leads. Reversed chest leads showed QS in V1-V3 with ST depression in V4-V6 associated with deep $\mathrm{T}$ wave inversion. Chest X-ray revealed dextrocardia with a right-sided aortic knob as well as gastric bubble. Echocardiography revealed left ventricle ejection fraction of $40 \%$ with hypokineses correspondent with ischemia in left anterior descending artery (LAD) territories and no significant valve disease. Cardiac catheterization was performed via the right radial artery using mirror-image views and standard Judkins catheters. A 5 French (Fr) angulated pigtail catheter was through the right-sided aortic knob into the left ventricle. The 300 left anterior oblique (LAO) ventriculogram (Figure 1) showed anterior wall hypokinesia and severe hypokises/ akineses of the apex and the inferior wall with an ejection fraction of $40 \%$. The ostium of the right coronary artery (RCA) was easily engaged by gentle counterclockwise rotation and slightly withdrawal of a $5 \mathrm{Fr}$ Judkins right $4 \mathrm{~cm}$ (JR4) diagnostic catheter in right-anterioroblique (RAO) and RAO-cranial views showed $100 \%$ lesion at midRCA segment (Figure 2). The ostium of the left main coronary artery was also cannulated using a 5 Fr Judkins left 4-cm (JL4) diagnostic catheter in a RAO view. The selective left coronary angiogram revealed $\mathrm{a}>70 \%$ tubular stenosis in the middle segment of LAD artery and a patent left circumflex (LCX) artery (Figure 3). Adhoc-PCI to LAD was performed with the use of 5 Fr JL 3.5 guide catheter and a 0.014 " balanced middleweight (BMW) guide wire. Two overlapping drug-eluting stents (Xience Prime $2.5 \times 28 \mathrm{~mm}$ and Promus Element $2.25 \times 12 \mathrm{~mm}$ ) were directly deployed at the site of the lesion in the middle segment of the LAD artery with good angiographic result (Figure 4). The patient experienced an uneventful post-PCI course and was discharged on the following day. He was free of angina on clinical follow-up. 


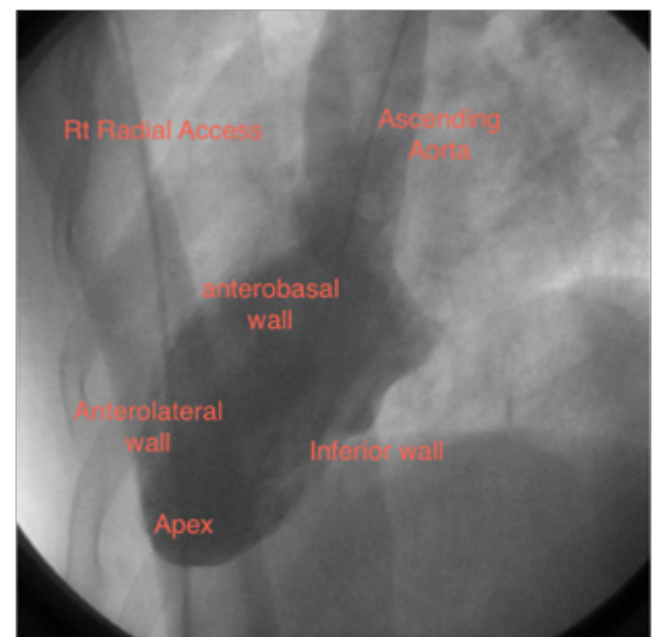

Figure I Left ventricle angiogram in left anterior oblique view $30^{\circ}$ showing mirror image anatomical configuration of the left ventricle in conventional right anterior oblique $30^{\circ}$ view.

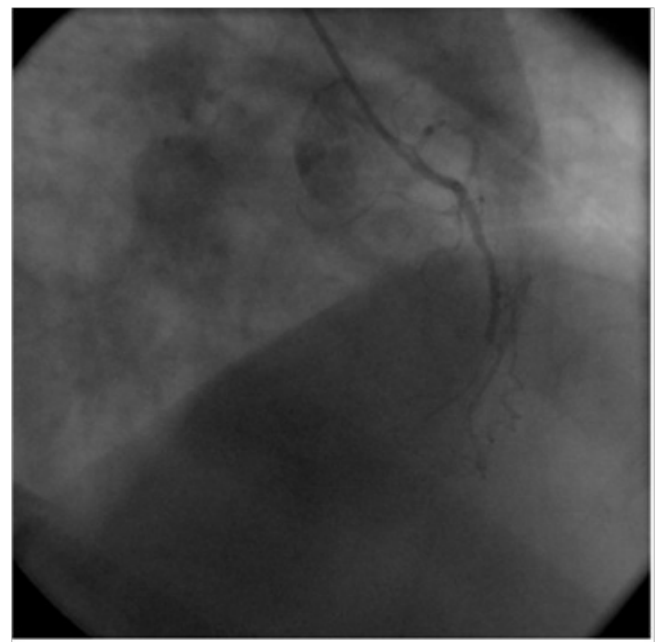

Figure 2 Right coronary artery (RCA) injections in right anterior-oblique view $45^{\circ}$ showing total occlusion in mid RCA. The anatomy is mirror image to $\mathrm{RCA}$ injection in conventional left anterior-oblique projection.

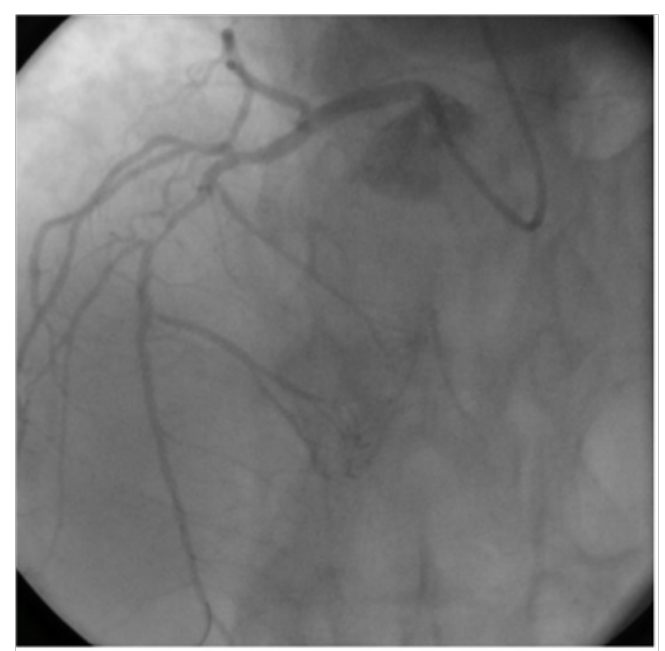

Figure 3 Left coronary angiogram in postero-anterior/cranial $40^{\circ}$ view showing significant lesion in mid left anterior descending artery (LAD). The anatomy is mirror image to the same view in normal case.

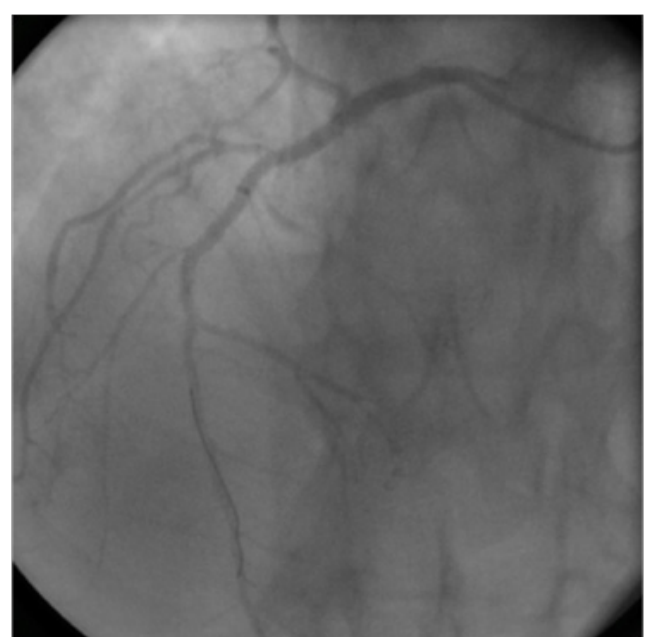

Figure 4 Post angioplasty left coronary angiogram in postero-anterior/ cranial injection showing normally flowing vessel. The image is mirror image to conventional poster-anterior/cranial projection for the left coronary system in normal situation.

\section{Discussion}

Dextrocardia refers to the position of the heart in the right side of the chest. It is a rare clinical phenomenon with a reported incidence of 1 in 5,000-30,000. ${ }^{1}$ In the absence of other structural heart disease, the life expectancy is usually normal. The association of coronary artery disease (CAD) in these patients is the same as in the general population. ${ }^{4}$ Hence, even elderly patients with this rare anomaly have been subjected to successful percutaneous or surgical intervention of CAD, as reported in literatures. ${ }^{5,6}$ The first cardiac catheterization in dextrocardia was reported in $1973,{ }^{7}$ the first coronary artertery bypass surgery in $1980^{8}$ and the first percutaneous intervention in dextrocardia performed in $1987 .{ }^{9}$

Presentation of patients with dextrocardia with variant myocardial ischemia symptoms of right-sided chest pain has been previously noted. ${ }^{10-12}$ The reason for this atypical presentation is unclear. Situs inversus has been previously shown to be associated with abnormal neural axis development ${ }^{13}$ and this may lead to variant visceral pain presentation. Afferent fibers from the heart traveling along the sympathetic trunks of the neck and thorax may enter the higher thoracic levels (T1 to T4/5) from the right rather than the left side, thus associating with spinal ganglia and spinal cord segments receiving sensory impulses from the right side of the body. This may also explain previous reports of ischemic pain referral down the right shoulder and arm in these patients. ${ }^{7,14,15}$ Pain localization from abdominal viscera is also discrepant and suggests that peripheral nerve route transposition occurs in about $50 \%$ of cases of situs inversus. Consequently, patients with dextrocardia may present with pain referred to either the left or the right side of the body. ${ }^{16}$ Moreyra et al.,${ }^{9}$ who first reported a case of percutaneous transluminal coronary angioplasty in dextrocardia with situs inversus, found Judkins catheters unhelpful and advocated using multipurpose catheters because their flexible tips allowed for easy manipulation into the coronary ostia. It has since been suggested that the suitability of diagnostic and interventional guide catheters can be predicted by the aortic arch position. ${ }^{17-19}$ In our experience, however, even in the presence of right-sided aortic arch, the left Judkins catheter can be used to cannulate the right-sided morphologically left coronary artery. Similarly, the right Judkins catheter manipulated to the mirror of its usual position can cannulate the left-sided morphological RCA. Notably, catheter rotation (torquing) is in the opposite direction of 
that employed for normal cardiac anatomy. Counterclockwise rotation is, for example, required to engage the left sided RCA with the right Judkins catheter. Successful employment of Judkins catheters has been previously reported in a case of dextroversion (dextrocardia with normally related atria and left-sided aortic arch). This is not surprising as in these patients the coronary artery ostia lay close to their usual positions. ${ }^{20}$ Consequently, contrary to previous reports, we suggest that the standard performed catheters may be employed in cases of dextrocardia with both right and left-sided aortic arch positions. A double-inversion technique of reversed image acquisition and horizontal inversion of on-screen display has been previously described. ${ }^{21}$ In our case, angiography and intervention were performed without on-screen reversal of the images. It is still necessary, however, to reverse the transverse angulations whilst maintaining the common cranial/caudal sagital tilts. A RAO caudal view, for example, produces a mirror image LAO caudal view. Although the double inversion technique makes the coronary tree appear "normal" with normal orientation, it also artificially reverses the on-screen response of catheters and angioplasty wires to normal manipulation (torquing). Consequently, although it may aid image interpretation, we found this technique unhelpful for PCI.

Trans-radial coronary angiography and angioplasty have emerged as safe, feasible, and effective alternative with similar results to those of the trans-femoral approach with negligible rate of major vascular complications. $^{22,23}$ Trans-radial PCI in dextrocardia was first reported in $2007^{24}$ and since then there are only 5 reports on transradial intervention in patients with dextrocardia ${ }^{25-29}$ out of which one patient underwent the procedure through left radial approach. In all of those reported cases, the operators used 6Fr-system but in our case we used 5Fr system successfully. Honda and his colleagues found that downsizing of the devices used in transradial procedures might attenuate access site-related bleeding or occlusive complications after transradial coronary angiography or $\mathrm{PCI} .{ }^{30}$

\section{Conclusion}

In summary, we report to our knowledge the first case of transradial PCI in dextrocardia using 5Fr system. We also report that transradial $\mathrm{PCI}$ is effective and safe in dextrocardia as well as it used to be in normal population. Standard Judkins catheters can be effectively used to cannulate right and left coronary arteries using counterclockwise catheter rotations and mirror-image views.

\section{Acknowledgement}

None.

\section{Conflicts of interest}

Authors declare that there are no conflicts of interest.

\section{References}

1. Solizbach U, Beuter M, Hartig B, et al. Isolated dextrocardia with situs solitus (Dextrocardia). Herz. 2010;35(3):207-210.

2. Perloff JK. The Clinical Recognition of Congenital Heart Disease. 2nd edition. WB Saunders Co, Philadelphia; 1978. p. 19-42.

3. Dhanjal TS, Davison P, Cotton JM. Primary percutaneous coronary intervention for acute myocardial infarction in a patient with dextrocardia. Cardiol J. 2009;16(2):168-171.

4. Hynes KM, Gau GT, Titus JL. Coronary heart disease in situs inversus totalis. Am J Cardiol. 1973;31(5):666-669.
5. Bonde P, Campalani GF. Myocardial revascularization for situs inversus totalis and dextrocardia. Interact Cardiovasc Thorac Surg. 2003;2(4):486-488.

6. Saadi EK, Dussin LH, Nicolao A, et al. Coronary artery bypass grafting in a patient with situs inversus totalis and dextrocardia. Rev Bras Cir Cardiovasc. 2007;22(3):346-348.

7. Ettinger PO, Brancato R, Penn D. Dextrocardia, anteroseptal infarction and fascicular block. Chest. 1975;68(2):229-230.

8. Irvin RG, Ballenger JF. Coronary artery bypass surgery in a patient with situs inversus. Chest. 1982;81(3):380-381.

9. Moreyra AE, Saviano GJ, Kostis JB.Percutaneous transluminal coronary angioplasty in situs inversus. Cathet Cardiovasc Diagn. 1987;13(2):114 116.

10. Salanitri JC, Welker M, Pereles FS. Magnetic resonance imaging of acute myocardial infarction in dextrocardia with situs solitus (dextroversion). Australas Radiol. 2005;49(5):422-426.

11. Ptashkin D, Stein E, Warbasse JR. Congenital dextrocardia with anterior wall myocardial infarction. Am Heart J. 1967;74(2):263-267.

12. Bhakta D, Breall JA, Kalaria VG. Complete situs inversus and bicuspid aortic valve stenosis. J Invasive Cardiol. 2003;15(4):213-215.

13. Tubbs RS, Wellons JC, Salter G, et al. Intracranial anatomic asymmetry in situs inversus totalis. Anat Embryol (Berl). 2003;206(3):199-202.

14. Liem KI, Ten Veen JH. Inferior myocardial infarction in a patient with mirror image dextrocardia and situs inversus totalis. Chest. 1976;69(2):239-241.

15. Alzand BS, Dennert R, Kalkman R, Gorgels AP (2009) Acute anteroseptal myocardial infarction in a patient with dextrocardia. $\mathrm{J}$ Electrocardiol 42(3):254-257.

16. Kakouros N, Patel SJ, Redwood S, et al.Triple-vessel percutaneous coronary revascularization in situs inversus dextrocardia. Cardiol Res Pract. 2010:606327.

17. Robinson N, Golledge P, Timmis A. Coronary stent deployment in situs inversus. Heart. 2001;86(5):E15.

18. Galgani R, Gabos K, Sangani BH. Coronary angioplasty in a patient with dextrocardia. Cathet Cardiovasc Diagn. 1989;17(1):45-47.

19. Blankenship JC, Ramires JAF. Coronary arteriography in a patient with dextrocardia. Cathet Cardiovasc Diagn. 1991;23(2):103-106.

20. Mehrotra P, Choi JW, Flaherty J, et al. Percutaneous coronary intervention in a patient with cardiac dextroversion. Proc (Bayl Univ Med Cent). 2006;19(3):226-228.

21. Goel PK. Double-inversion technique for coronary angiography viewing in dextrocardia. Catheter Cardiovasc Interv. 2005;66(2):281-285.

22. Agostoni P, Biondi-Zoccai CG, de Benedictis MI, et al. Radial versus femoral approach for percutaneous coronary diagnostic and interventional procedures; systematic overview and meta-analysis of randomized trials. J Am Coll Cardiol. 2004;44(2):349-356.

23. Jolly SS, Yusuf S, Cairns J, et al. Radial versus femoral access for coronary angiography and intervention in patients with acute coronary syndromes (RIVAL): a randomized, parallel group, multicentre trial. Lancet. 2011;377(9775):1409-1420.

24. Chen JP. Repeat right transradial percutaneous coronary intervention in a patient with dextrocardia: the right approach to the right-sided heart. Catheter Cardiovasc Interv. 2007;69(2):223-226.

25. Jang GS, Kim HS, Lee WY, et al. Left transradial coronary angiography in a patient with dextrocardia. Korean Circ J. 2010;40(11):601-603. 
26. Zhao ZW, Lin CG, Chen LL. Repeat right transradial intervention in 9 days in a patient with dextrocardia and situs inversus. Tex Heart Inst J. 2010;37(6):734-735

27. Ishigure H, Murohara T, Ikari Y. The feasibility of using Ikari left catheter via the right radial approach in a patient with dextrocardia for better guiding support. J Invasive Cardiol. 2011;23(12):E288-E290.

28. Showkathali R, Davies JR. Transradial rotablation in a patient with dextrocardia and acute ST-elevation myocardial infarction. Interv Med Appl Sci. 2012;4(4):221-223.
29. Goel PK, Moorthy N. Trans-radial primary percutaneous coronary intervention in dextrocardia using double inversion technique. Journal of Cardiology Cases. 2013;8(1):e31-e33.

30. Honda T, Fujimoto K, Miyao Y, et al. Access site-related complications after transradial catheterization can be reduced with smaller sheath size and statins. Cardiovasc Interv Ther. 2012;27(3):174-180. 